\title{
Composição do ganho e exigências de energia e proteína para ganho de peso em bovinos Nelore puros e mestiços ${ }^{1}$
}

\author{
José Antônio de Freitas ${ }^{2}$, Augusto César de Queiroz ${ }^{3}$, Alecssandro Regal Dutra ${ }^{4}$, Ricardo \\ Augusto Mendonça Vieira ${ }^{5}$, Rogério de Paula Lana ${ }^{3}$, Fernando de Paula Leonel ${ }^{6}$, Douglas \\ Sampaio Henrique ${ }^{6}$, Adhemar Ventura de Lima $^{7}$, Júlio César de Souza ${ }^{2}$
}

\author{
1 Parte da tese de Doutorado em Zootecnia apresentada à Universidade Federal de Viçosa pelo primeiro autor. Apoio: CAPES \\ 2 Universidade Federal do Paraná - Palotina - PR. \\ 3 Universidade Federal de Viçosa - Viçosa - MG. \\ 4 Universidade Estadual de Goiás - Goiânia - GO. \\ 5 Professor da UENF - Campos dos Goytacazes - RJ. \\ ${ }^{6}$ Doutorando em Zootecnia - Universidade Federal de Viçosa. \\ 7 Zootecnista.
}

RESUMO - Objetivou-se estimar a composição do ganho e as exigências de energia e proteína para ganho de peso em bovinos Nelore puros e mestiços. Utilizaram-se 60 bovinos machos (Nelore, F1 Nelore x Angus, F1 Nelore x Pardo-Suíço e F1 Nelore x Simental) não-castrados, com 10 a 11 meses de idade e peso médio inicial de 286, 309, 333 e $310 \mathrm{~kg}$, respectivamente. $\mathrm{O}$ delineamento utilizado foi o inteiramente casualizado, com quatro grupos genéticos, submetidos a quatro níveis de concentrado na ração $(30,40,60$ e 70\%). Três animais de cada grupo genético foram abatidos ao início do experimento e serviram como referência na determinação da composição corporal inicial. As exigências líquidas de proteína e energia para ganho de $1 \mathrm{~kg}$ de peso corporal vazio $(\mathrm{PCV})$ foram estimadas pela equação $\mathrm{Y}^{\prime}=\mathrm{a} \cdot \mathrm{b} \cdot \mathrm{X}^{(\mathrm{b}-1)}$, em que a e b são os coeficientes das equações de regressão dos conteúdos de energia e proteína e X, o PCV dos animais. O teste de identidade de modelos não-lineares indicou não haver diferenças entre grupos genéticos para as exigências de energia e proteína para ganho de peso. Verificou-se decréscimo de 10,6\% nas exigências de proteína e elevação de 37,8\% nas exigências de energia para ganho de peso entre 250 e $550 \mathrm{~kg}$, o que está relacionado à elevação do teor de gordura e à redução no teor de proteína com o acréscimo no PCV. As exigências líquidas de proteína e energia para ganho de peso foram estimadas em 143,5 g e 4,7 Mcal para o peso vivo de $450 \mathrm{~kg}$.

Palavras-chave: bovinos de corte, exigências energéticas

\section{Gain composition and net energy and protein requirements for weight gain in Nellore and crossbred cattle}

\begin{abstract}
The objectives of this trial were to estimate gain composition and energy and protein requirements for weight gain of purebred and crossbred Nellore. Sixty young bulls averaging 10 to 11 months of age from four genetic groups: Nellore, F1 Nellore x Angus, F1 Nellore x Brown Swiss and F1 Nellore x Simental and initial average body weights of 286 , 309,333 and $310 \mathrm{~kg}$, respectively, were used in this study. A completely randomized design was adopted and bulls from the four genetic groups were fed diets containing: 30, 40, 60 and 70\% of concentrate. Three animals from each genetic group were slaughtered at the beginning of the trial and used as reference for initial body composition. The net protein and energy requirements for gain of $1 \mathrm{~kg}$ of empty body weight (EBW) were estimated by the equation $\mathrm{Y}^{\prime}=\mathrm{a} . \mathrm{b} . \mathrm{X}^{(\mathrm{b}-1)}$, where $\mathrm{a}$ and $\mathrm{b}$ are the parameters of the regression equations and $\mathrm{X}$ is the EBW of the animals. The identity test of the models indicated no significant differences among genetic groups for the net energy and protein requirements for weight gain. It was observed a decrease of $10.6 \%$ and an increase of $37.8 \%$, respectively, in the protein and energy requirements for body weight gain between 250 and $550 \mathrm{~kg}$. These changes are result of the increase in the content of fat and reduction in that of protein as EBW increased. The net requirements of protein and energy for body weight gain were estimated as $143.5 \mathrm{~g}$ and 4.7 Mcal, respectively, for a body weight of $450 \mathrm{~kg}$.
\end{abstract}

Key Words: beef cattle, body protein, crossbred, energy requirements

\section{Introdução}

Após o nascimento, os bovinos iniciam uma fase de crescimento que pode ser representada por uma curva do tipo sigmóide, que possui inclinação crescente do nascimento à puberdade $\mathrm{e}$, a partir deste estádio, apresenta uma fase de desaceleração do crescimento, caracterizada pelo aumento na taxa de deposição de gordura e pela diminuição 
na taxa de deposição de proteína. Esse comportamento é acompanhado pelo aumento nas exigências de energia e redução nas de proteína para ganho de peso com a elevação do peso do animal. Dessa forma, é importante o adequado suprimento das exigências de energia e proteína visando proporcionar altos índices produtivos e econômicos.

A energia e a proteína têm sido consideradas essenciais na nutrição animal, haja vista sua importância para o desenvolvimento e também o fato de serem responsáveis pela maior fração do custo da alimentação nos sistemas de produção. Geralmente, a maior proporção da energia utilizada pelos ruminantes provém da fermentação da fibra no rúmen (Van Soest, 1994).

As exigências de proteína para os bovinos são supridas pelo total de aminoácidos absorvidos no intestino (proteína metabolizável), resultantes do somatório entre a proteína dietética e os aminoácidos da proteína microbiana. As exigências energéticas e protéicas em bovinos em crescimento e terminação estão relacionadas à relação músculo/gordura no ganho de peso e, segundo o NRC (1996), podem variar de acordo com a raça, o peso, o estádio fisiológico e a condição sexual dos animais, além de outros fatores, como a taxa de ganho de peso e o uso de hormônios anabolizantes.

O NRC (1996) postula que raças de maior tamanho à maturidade (mais tardias para a deposição de tecido adiposo) apresentam, a uma mesma taxa de ganho, maiores teores de proteína (em relação à gordura) e mais altas exigências de proteína para ganho de peso e, portanto, possuem também menores exigências líquidas de energia e maiores de proteína para ganho de peso. De forma semelhante, Toelle et al. (1986) verificaram influência do grupo genético sobre as exigências de proteína e energia para ganho de peso e observaram que bovinos de menor peso à maturidade apresentavam maior teor de gordura no ganho que os de maior tamanho à maturidade.

Fontes (1995) constatou, em bovinos mestiços e Nelore, redução nas exigências de proteína com o aumento do peso corporal dos animais. Resultados semelhantes aos obtidos por esse autor foram registrados também por Lana et al. (1992), Pires et al. (1993), Estrada et al. (1997), Verás et al. (2000) e Almeida et al. (2001), que verificaram decréscimos nas exigências líquidas de proteína e elevação nos teores de gordura no ganho e nas exigências de energia para ganho com o aumento do peso dos animais.

Silva et al. (2002), compilando dados de 14 pesquisas envolvendo 581 bovinos Zebu, mestiços F1 Europeu x Zebu, mestiços leiteiros e Holandês, notaram que os zebuínos possuem maior exigência de energia e menor de proteína para ganho de peso.

Toelle et al. (1986) verificaram que o peso ao abate tem grande influência sobre a composição do ganho. $\mathrm{O}$ aumento nas exigências de energia para ganho de peso com o aumento do peso de abate está relacionado à maior deposição de gordura no ganho, que apresenta maior equivalente calórico. Portanto, quanto maior a energia retida no ganho, maiores as exigências de energia para ganho de peso.

Fontes (1995), analisando resultados de várias pesquisas com bovinos zebuínos e mestiços Zebu x Europeu, relatou que as exigências de proteína para ganho decrescem com o aumento do peso corporal vazio do animal, enquanto o conteúdo de gordura no ganho e as exigências de energia para ganho apresentam comportamento inverso. Quanto à condição sexual, o autor constatou que animais não-castrados apresentavam menor exigência líquida de energia e maior de proteína para ganho de peso que os animais castrados.

O NRC (1996) assume que o grande número de raças de bovinos, a diversidade de cruzamentos, a utilização de agentes anabolizantes, a condição sexual dos animais e os sistemas de alimentação e de classificação de carcaça adotados na América do Norte tornam os sistemas Europeu (ARC) e Australiano (CSIRO), utilizados para estimar as exigências de energia e proteína, impróprios às condições norte-americanas. Por motivos semelhantes, os sistemas estrangeiros para determinação das exigências de energia e proteína não são apropriados para as condições tropicais, o que justifica o desenvolvimento de pesquisas sobre as exigências nutricionais, a fim de se obter maior número de informações para elaboração de uma tabela de exigências nutricionais de animais nas condições tropicais.

Desse modo, o conhecimento mais preciso da composição corporal e das exigências de energia e proteína para ganho de peso dos animais, bem como do valor nutricional dos alimentos, é fundamental para o balanceamento de rações de mínimo custo, de forma a permitir melhor aproveitamento do potencial genético dos animais, de maneira economicamente viável, e, desse modo, produzir carne de excelente valor nutritivo a um custo acessível para a maioria da população.

Objetivou-se com este trabalho estimar o conteúdo de gordura no ganho de peso e as exigências líquidas de proteína e energia para ganho de peso em bovinos Nelore puros e mestiços. 


\section{Material e Métodos}

A pesquisa foi conduzida no Instituto Melon de Estudos e Pesquisas, localizado na Fazenda Barreiro, em Silvânia, Goiás, no período de maio a agosto de 2000. As análises bromatógicas foram realizadas no Laboratório de Nutrição Animal do Departamento de Zootecnia da Universidade Federal de Viçosa, Minas Gerais.

O município de Silvânia localiza-se no planalto central goiano e possui clima mesotérmico e úmido, segundo a classificação de Köppen. A temperatura média anual é de $22^{\circ} \mathrm{C}$, com variação média de $5^{\circ} \mathrm{C}$ ao longo do ano. A precipitação pluviométrica anual $(1.450 \mathrm{~mm})$ caracteriza-se por uma distribuição periódica, com duas estações bem definidas, com maior concentração das chuvas no período de novembro a março.

Adotou-se delineamento inteiramente casualizado, em arranjo fatorial $4 \times 4$ (quatro níveis de concentrado e quatro grupos genéticos), com três repetições por tratamento. Foram utilizados 60 bovinos machos inteiros, com idade inicial de 10 a 11 meses, sendo 15 Nelore, 15 F1 Nelore x Angus, 15 F1 Nelore x Pardo-Suíço e 15 F1 Nelore x Simental, compeso médio inicial de $286,309,333$ e $310 \mathrm{~kg}$, respectivamente. Foram utilizadas quatro proporções volumoso:concentrado (30:70, 40:60, 60:40 e 70:30) e três animais de cada grupo genético por tratamento, perfazendo um total de 12 animais. Os animais foram mantidos em baias individuais de $16 \mathrm{~m}^{2}\left(8 \mathrm{~m}^{2}\right.$ de área concretada e $8 \mathrm{~m}^{2}$ de piso batido), parcialmente cobertas, providas de comedouro individual $(0,8 \mathrm{~m}$ de largura, $0,6 \mathrm{~m}$ de parede externa e $0,5 \mathrm{~m}$ de parede interna) e de um bebedouro concretado $(1,0 \times 1,0 \mathrm{~m})$ para cada duas baias.

As rações foram formuladas de acordo com as recomendações do NRC (1996) e seu fornecimento era feito uma vez ao dia, de modo a permitir sobras de 10 a $20 \%$ da quantidade ofertada. Diariamente, foram registradas as quantidades de ração fornecida e das sobras e, semanalmente, foram coletadas amostras individuais dos alimentos e das sobras, que, a cada sete semanas, compuseram uma amostra representativa do período.

Nas Tabelas 1 e 2 são descritas a composição química do feno e dos concentrados e a composição bromatológica das rações experimentais.

Paralelamente a este ensaio, foi realizado outro, no qual foram determinados os coeficientes de digestibilidade aparente e total. As determinações de MS, PB, FDN, EE e minerais foram feitas conforme técnicas descritas por Silva \& Queiroz (2002). Os carboidratos totais (CT) foram obtidos pela equação $\mathrm{CT}(\% \mathrm{MS})=100-[\mathrm{PB}(\% \mathrm{MS})+\mathrm{EE}(\% \mathrm{MS})+\mathrm{MM}$ $(\% \mathrm{MS})]$ e os NDT pela equação NDT $\mathrm{N}_{\text {aparente }}(\mathrm{g} / \mathrm{dia})=(\mathrm{PB}$
Tabela 1 - Composição química do feno e dos concentrados utilizados nas dietas experimentais, expressa na MS

Table 1 - Chemical composition of hay and concentrates used in the experimental diets, expressed in DM basis

\begin{tabular}{lccccc}
\hline $\begin{array}{l}\text { Nutriente } \\
\text { Nutrient }\end{array}$ & $\begin{array}{c}\text { Feno } \\
\text { Hay }\end{array}$ & \multicolumn{4}{c}{$\begin{array}{c}\text { Tipo de concentrado } \\
\text { Type of concentrate }\end{array}$} \\
\cline { 3 - 6 } & & Conc.70 & Conc60 & Conc40 & Conc30 \\
\hline MS (DM) & 83,83 & 89,49 & 89,37 & 89,25 & 89,20 \\
PB (CP) & 7,86 & 29,2 & 25,0 & 19,09 & 17,0 \\
FDN (NDF) & 74,66 & 10,51 & 10,87 & 11,24 & 11,35 \\
CHT (TC) & 88,50 & 71,68 & 73,92 & 76,18 & 76,34 \\
NDT (TDN) & 52,90 & 76,90 & 78,17 & 79,39 & 79,65 \\
EE (EE) & 0,68 & 3,00 & 3,17 & 3,34 & 3,38 \\
CZ (Ash) & 6,34 & 10,44 & 9,65 & 8,96 & 8,72 \\
\hline
\end{tabular}

Tabela 2 - Composição química das rações, expressas na matéria seca, para as diferentes relações volumoso: concentrado

Table 2 - $\quad$ Chemical composition of diets varying on forage to concentrate ratio, expressed in dry matter basis

\begin{tabular}{lcccc}
\hline $\begin{array}{l}\text { Nutriente } \\
\text { Nutrient }\end{array}$ & \multicolumn{4}{c}{$\begin{array}{c}\text { Relação volumoso:concentrado } \\
\text { Forage:concentrate ratio }\end{array}$} \\
\cline { 2 - 5 } & $70: 30$ & $60: 40$ & $40: 60$ & $30: 70$ \\
\hline MS (DM) & 91,43 & 91,11 & 90,45 & 90,12 \\
PB (CP) & 14,3 & 14,7 & 14,6 & 14,3 \\
FDN (NDF) & 51,83 & 46,08 & 34,56 & 28,82 \\
CHT (TC) & 83,35 & 82,59 & 81,07 & 79,96 \\
NDT (TDN) & 60,1 & 63,0 & 68,8 & 71,6 \\
EE (EE) & 1,39 & 1,69 & 2,29 & 2,57 \\
EM (ME) & 2,17 & 2,28 & 2,49 & 2,59 \\
CZ (Ash) & 7,59 & 7,68 & 7,92 & 8,01 \\
\hline
\end{tabular}

[EM] determinada - expressa em $\mathrm{kcal} / \mathrm{kg}$ de MS

Determined [ME]- expressed in $\mathrm{kcal} / \mathrm{kg}$ of DM.

ração $-\mathrm{PB}$ fezes $)+(\mathrm{CT}$ ração $-\mathrm{CO}$ fezes $)+2,25$ (EE ração - EE fezes), segundo Sniffen et al. (1992).

A duração do experimento não foi pré-definida, visto que os animais eram abatidos quando atingiam 100 ou $110 \%$ do peso correspondente ao das fêmeas do mesmo grupo genético. Todos os animais, independentemente do grupo genético, foram abatidos, após jejum de 14 horas, aos 480 $510 \mathrm{~kg}$ de PV. A diferença no peso de abate dos animais pode ser atribuída à variação do peso dentro dos lotes de animais abatidos. De cada animal abatido, foram pesadas e coletadas amostras representativas dos órgãos, das vísceras e da carcaça. As amostras de carne (120 g), gordura ( $200 \mathrm{~g}$ ) vísceras $(200 \mathrm{~g})$ e couro $(100 \mathrm{~g})$, depois de moídas, foram armazenadas em vidros com capacidade de $250 \mathrm{~mL}$ e mantidas em estufa a $105^{\circ} \mathrm{C}$ durante 48 a 72 horas, para determinação da matéria seca gordurosa (MSG). Em seguida, foram submetidas a um processo de extração de gordura com éter de petróleo, conforme descrito por Kock \& Preston (1979), obtendo-se a matéria seca pré-desengordurada (MSPD), que, posteriormente, foi processada em moinho de bola, 
antes de se proceder às análises de nitrogênio total, EE e cinzas. As amostras de sangue ( $400 \mathrm{~g}$ ) foram coletadas imediatamente após o abate, acondicionadas em pirex, encaminhadas à estufa de ventilação forçada $\left(55^{\circ} \mathrm{C}\right)$, durante 48 horas, para determinação dos teores de matéria pré-seca, sendo, posteriormente, processadas em moinho de bola. As determinações de NDT foram feitas em aparelho semimicro kjedahl e as de EE, em aparelho soxhlet, conforme descrito por Silva \& Queiroz (2002).

As carcaças foram pesadas no dia do abate, realizando-se no mesmo dia a coleta de amostra representativa da meiacarcaça esquerda, correspondente à secção da 9 à $11^{1}$ a costela, de acordo com a metodologia proposta por Hankins \& Howe (1946). A partir das proporções de músculo, tecido adiposo e ossos na seção HH, estimaram-se suas proporções na carcaça, por meio das equações descritas por Hankis \& Howe (1946).

$$
\begin{aligned}
& \text { Músculo: } \quad \mathrm{Y}=16,08+0,80 \mathrm{X} \\
& \text { Tecido adiposo: } \mathrm{Y}=3,54+0,89 \mathrm{X} \\
& \text { Osso: } \quad \mathrm{Y}=5,52+0,57 \mathrm{X}
\end{aligned}
$$

em que X é a porcentagem dos componentes na secção HH.

Ao início do experimento, foram abatidos 12 animaisreferência (três de cada grupo genético), para estimava da composição corporal inicial dos animais remanescentes.

O peso de corpo vazio (PCV) dos animais foi determinado pelo somatório dos pesos de carcaça, sangue, cabeça, couro, pés, cauda, vísceras e órgãos. A relação entre o peso de corpo vazio (PCV) e o peso vivo dos animais-referência de cada grupo genético foi utilizada para estimativa do PCV inicial dos animais remanescentes dos diversos grupos genéticos. Os conteúdos corporais de gordura (GO) e proteína bruta $(\mathrm{PB})$ foram determinados considerando-se suas concentrações percentuais nos tecidos, nos órgãos, no couro, no sangue e na amostra representativa da carcaça (corte da 9 $\underline{a}, 10 \underline{a}$ e $11 \underline{a}$ costelas). Foram determinados nos tecidos corporais, nos órgãos, no couro e no sangue de cada animal os teores de matéria seca gordurosa (MSG) e água (AG). A MSG foi tratada com éter de petróleo a fim de se extrair parte da gordura e obter a matéria seca prédesengordurada (MSPD). Subtraindo-se a MSPD da MSG, obteve-se a gordura extraída no pré-desengorduramento. A partir da MSPD dos tecidos, amostras representativas das carcaças (carne, gordura e osso) foram moídas, efetuando-se as análises de nitrogênio total, extrato etéreo e cinzas, conforme a técnica descrita por Silva \& Queiroz (2002), possibilitando determinar a composição da matéria natural. A determinação dos conteúdos corporais de energia foi realizada pelo produto dos conteúdos corporais de proteína e gordura pelos seus respectivos equivalentes calóricos, conforme a equação proposta pelo ARC (1980).

$$
\mathrm{CE}(\mathrm{Mcal})=(5,6405 \mathrm{X}+9,3929 \mathrm{Y})
$$

em que $\mathrm{CE}=$ conteúdo de energia da carcaça, em $\mathrm{kg}$; $\mathrm{X}=$ proteína corporal, em $\mathrm{kg}$; $\mathrm{Y}=$ gordura corporal, em $\mathrm{kg}$.

Os conteúdos líquidos de energia, gordura e proteína retidos no corpo dos animais foram estimados por meio do ajuste de equações de regressão do conteúdo corporal de energia e proteína, em função do PCV, de acordo com a equação:

$$
Y_{i j k}=a \cdot X_{i j k}^{b}+e_{i j k}
$$

em que: $\mathrm{Y}_{\mathrm{ijk}}=$ conteúdo total de energia (Mcal) ou proteína $(\mathrm{kg})$ no corpo vazio do animal $\mathrm{j}$, do grupo genético i, pertencente ao tratamento $\mathrm{k} ; \mathrm{a}=$ constante; $\mathrm{b}=$ coeficiente de regressão dos conteúdos de gordura, energia e proteína, em função do PCV; $X_{i j k}=$ peso de corpo vazio do animal $j$, do grupo genético $\mathrm{i}$, do tratamento $\mathrm{k} ; \mathrm{e}_{\mathrm{ijk}}=$ erro aleatório associado a cada observação.

As exigências líquidas de energia e proteína para ganho de $1 \mathrm{~kg}$ de PCV foram obtidas pela derivada das equações de predição do conteúdo corporal de energia e proteína a partir da equação: $Y^{\prime}=a \cdot b \cdot X^{(b-1)}$, em que a e b são coeficientes de regressão e $\mathrm{X}$, o PCV dos animais.

Os dados obtidos foram analisados por meio de análises de regressão e variância, pelo programa computacional SAS (Statistical Analyses System, 1995), aplicando-se o teste $\mathrm{F}$ a $5 \%$ de probabilidade aos coeficientes de regressão.

$\mathrm{Na}$ comparação entre grupos genéticos, quanto à composição corporal e às exigências de energia para mantença, utilizou-se o teste de identidade de modelos não-lineares, de acordo com técnica proposta por Regazzi (2003), para se verificar a possibilidade de utilização de um modelo em comum para todos os grupos genéticos ou de um modelo para cada grupo genético. O procedimento estatístico consiste no teste das seguintes hipóteses: $\mathrm{Ho}^{(1)}: \mathrm{a} 1=\mathrm{a} 2=\mathrm{a} 3=\mathrm{a} 4$, $\mathrm{Ha}^{(1)}$ : pelo menos um $\mathrm{a}_{\mathrm{i}}$ é diferente dos demais: $\mathrm{Ho}^{(2)}$ : $\mathrm{b} 1=\mathrm{b} 2=\mathrm{b} 3=\mathrm{b} 4, \mathrm{Ha}^{(2)}$ : pelo menos um $\mathrm{b}_{\mathrm{i}}$ é diferente dos demais; $\mathrm{Ho}^{(3)}: \mathrm{a} 1=\mathrm{a} 2=\mathrm{a} 3=\mathrm{a} 4 \mathrm{e} \mathrm{b} 1=\mathrm{b} 2=\mathrm{b} 3=\mathrm{b} 4 ; \mathrm{Ha}^{(3)}$ pelo menos uma igualdade é uma desigualdade.

\section{Resultados e Discussão}

Constam na Tabela 3 os parâmetros ( $a$ e b) das equações utilizadas para estimativa dos conteúdos de gordura e proteína ( $\mathrm{g} / \mathrm{kg}$ GPCV) no ganho e das exigências líquidas de energia para ganho de $1 \mathrm{~kg}$ de peso corporal vazio (GPCV), bem como seus coeficientes de determinação.

O conteúdo de gordura no GPCV e as exigências de proteína e energia para ganho PCV encontram-se na Tabela 4. Para conversão das exigências nutricionais de ganho de PCV em ganho de PV, adotou-se o fator 0,8793 , obtido a partir dos dados experimentais. 
Tabela 3 - Equações de predição do conteúdo corporal de gordura (g) no ganho e das exigências de proteína e energia para ganho de peso de bovinos Nelore, puros e mestiços, com 250 a $550 \mathrm{~kg}$ de PV

Table 3 - Prediction equations for body contents of fat $(\mathrm{g})$ and protein and energy requirements for weight gain of purebred and crossbred Nellore young bulls from 250 to $550 \mathrm{~kg}$ of body weight

\begin{tabular}{lcc}
\hline $\begin{array}{l}\text { Componente } \\
\text { Component }\end{array}$ & $\begin{array}{c}\text { Equação de predição } \\
\text { Prediction equation }\end{array}$ & $\mathrm{r}^{2}$ \\
\hline $\begin{array}{l}\text { Proteína (Protein) } \\
\text { Gordura (Fat) }\end{array}$ & $\mathrm{Y}=0,3444 . \mathrm{X}^{0,1458}$ & 0,94 \\
Energia (Energy) & $\mathrm{Y}=0,00447 . \mathrm{X}^{1,6711}$ & 0,91 \\
\hline
\end{tabular}

O teste de identidade de modelos não-lineares proposto por Regazzi (2003) indicou não haver diferenças entre grupos genéticos quanto às exigências nutricionais de proteína e energia e quanto ao teor de gordura no ganho de peso, a $5 \%$ de probabilidade. Portanto, adotou-se uma única equação para estimativa do conteúdo de gordura no ganho e das exigências líquidas de proteína e energia para ganho de peso.

Foram constatados aumentos nas exigências de energia para ganho e no conteúdo de gordura no ganho. Verificou-se também redução nas exigências líquidas de proteína para ganho de peso (Tabela 4), como resultado do aumento progressivo na deposição de gordura, em detrimento da deposição de proteína com a elevação do PCV dos animais.

Considerando a faixa de peso de 250 a $550 \mathrm{~kg}$, verificou-se elevação de $57,1 \%$ no conteúdo de gordura no ganho de $37,8 \%$ nas exigências de energia para ganho de peso. Comportamento inverso foi verificado para exigências de proteína para ganho de peso, as quais decresceram em $10,6 \%$, dentro da faixa de peso supracitada.

$\mathrm{O}$ aumento no teor de energia no ganho de peso (energia retida) também é influenciado pelo consumo de energia metabolizável (CEM)e pelo ganho de peso, conforme ilustrado nas Figuras 1 e 2, respectivamente.

O modelo que melhor descreveu o efeito do consumo de energia metabolizável sobre a energia retida foi o linear (Figura 1), embora seja diferente do modelo exponencial adotado por Ferrell \& Jenkins (1998) e Véras et al. (2000), que relataram aumento assintótico da ER decorrente do consumo de EM, indicando diminuição da eficiência de utilização da energia para ganho, à medida que se elevou o CEM (Ferrell \& Jenkins, 1998).

Observou-se aumento quadrático na energia retida com o aumento do ganho de peso, o que pode estar associado ao maior conteúdo de gordura no ganho conforme aumentou

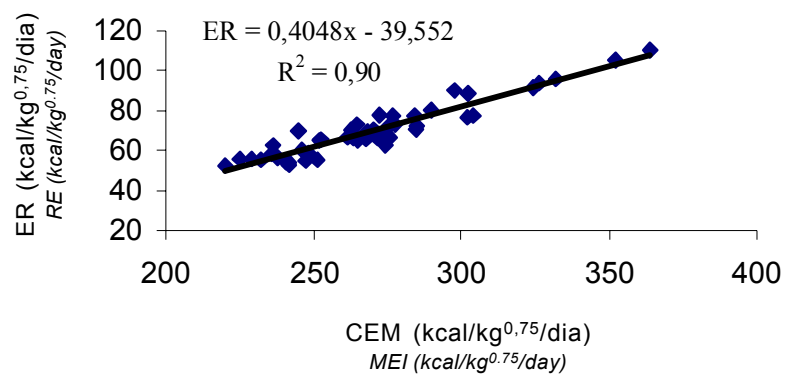

Figura 1 - Relação energia retida no ganho $\left(\mathrm{kcal} / \mathrm{kg}^{0,75} / \mathrm{dia}\right) \times$ consumo de energia metabolizável ( $\mathrm{kcal} / \mathrm{kg}^{0,75} / \mathrm{dia}$ ) em bovinos Nelore, puros e mestiços, com 250 e 550 $\mathrm{kg}$ de PV.

Figure 1 - Relationship between retained energy for gain ( $k$ cal $/ \mathrm{kg}^{0.75} / \mathrm{day}$ ) and metabolizable energy intake ( $\mathrm{kcal} / \mathrm{kg}^{0.75} /$ day) of purebred and crossbred Nellore young bulls from 250 to $550 \mathrm{~kg}$ of body weight.

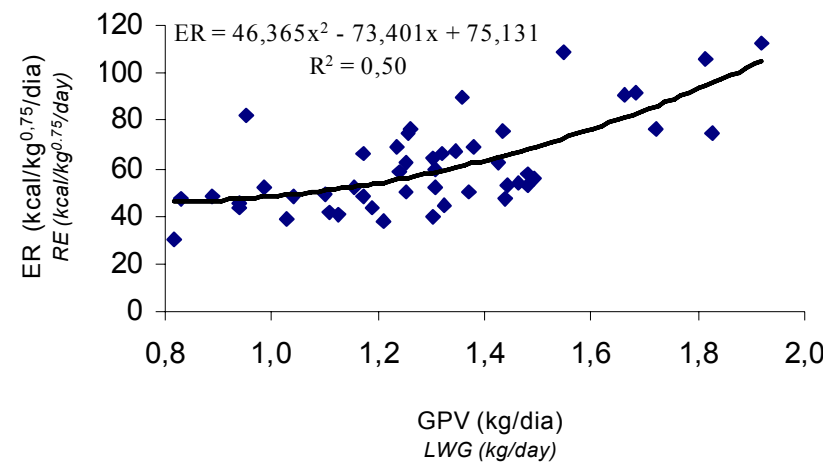

Figura 2 - Relação energia retida no ganho $\left(\mathrm{kcal} / \mathrm{kg}^{0,75} / \mathrm{dia}\right) \times$ ganho de peso (kg/dia) em bovinos Nelore, puros e mestiços, com 250 a $550 \mathrm{~kg} \mathrm{PV}$.

Figure 2 - Relationship between retained energy forgain (kcal/ $\left./ \mathrm{kg}^{0.75} / \mathrm{day}\right)$ and weight gain ( $\mathrm{kg} / \mathrm{day})$ of purebred and crossbred Nellore young bulls from 250 to $550 \mathrm{~kg}$ of body weight.

Tabela 4 - Conteúdo de gordura (kg/kg GPCV) e exigências de proteína (g/kg GPCV) e energia (Mcal/kg GPCV) para ganho de PCV em bovinos Nelore, puros e mestiços, com 250 a $550 \mathrm{~kg}$ de PV

Table 4 - Fat content ((kg/kg EBWG) and protein ( $/ \mathrm{kg}$ EBWG) and energy requirements (Mcal/kg EBWG) for empty body weight gain of purebred and crossbred Nellore young bulls from 250 to $550 \mathrm{~kg}$ of body weight

\begin{tabular}{lcccc}
\hline PV $(\mathrm{kg})$ & $\begin{array}{c}\text { PCV }(\mathrm{kg}) \\
E B W(\mathrm{~kg})\end{array}$ & $\begin{array}{c}\text { Proteína }(\mathrm{g} / \mathrm{kg} \mathrm{PCV}) \\
\text { Protein }(g / \mathrm{kg} E B W G)\end{array}$ & $\begin{array}{c}\text { Gordura }(\mathrm{g} / \mathrm{kg} \mathrm{GPCV}) \\
\text { Fat }(g / \mathrm{kg} \text { EBWG) }\end{array}$ & $\begin{array}{c}\text { Energia }(\mathrm{Mcal} / \mathrm{kg} \mathrm{GPCV}) \\
\text { Energy }(M c a l / k g E B W G)\end{array}$ \\
\hline 250 & 228,9 & 156,0 & 286,3 & 3,7 \\
300 & 272,8 & 152,0 & 322,1 & 4,0 \\
350 & 316,8 & 148,8 & 356,1 & 4,2 \\
400 & 360,8 & 146,0 & 388,6 & 4,5 \\
450 & 404,7 & 143,5 & 419,7 & 4,7 \\
500 & 448,7 & 141,4 & 449,8 & 4,9 \\
550 & 492,7 & 139,5 & 449,8 & 5,1 \\
\hline
\end{tabular}


o ganho de peso (Figura 2), como relatado por Berndt et al. (2002).

Para um bovino com $400 \mathrm{~kg}$ de peso vivo, as exigências líquidas de energia e proteína para ganho de peso foram estimadas em 4,5 Mcal/kg GPCV e $146 \mathrm{~g} / \mathrm{kg} \mathrm{GPCV}$, respectivamente (Tabela 4).

O comportamento das exigências de energia e proteína para ganho de peso pode ser explicado pelas modificações na curva de crescimento. Segundo Owens (1993), a curva de crescimento dos bovinos pode ser representada por uma sigmóide com duas fases distintas, que se caracterizam por tendências bastante diferentes. Na primeira fase, o crescimento é acelerado, em razão do desenvolvimento dos tecidos ósseo e muscular, ativado pela liberação dos hormônios protéicos de crescimento tiroxina e somatotropina (hormônio do crescimento), ocorrendo maior síntese de tecido muscular em relação ao adiposo. A segunda fase é caracterizada pela redução na intensidade de crescimento corporal, intensificando a deposição de tecido adiposo. Essa taxa de deposição de gordura corporal é influenciada também pela condição sexual; fêmeas tendem a depositar maior quantidade de gordura corporal com o aumento do peso e da idade, seguidas pelos machos não-castrados e pelos machos castrados. Comportamento inverso pode ser verificado para a taxa de deposição de proteína (Reid et al., 1980).

Além da reduzida idade (10 a 11 meses) dos animais utilizados neste estudo, o peso vivo inicial médio se encontrava acima do ponto em que, segundo Geay (1984), ocorre a máxima deposição de proteína. Desse modo, o decréscimo nas exigências de proteína pode estar relacionado à desaceleração no crescimento do tecido muscular. Entretanto, a redução na taxa de deposição de proteína, em bovinos, está associada a aumentos no desenvolvimento do tecido adiposo, que resultam em acréscimos nas exigências de energia para ganho de peso com o aumento do peso vivo dos animais.

Elevação no conteúdo corporal de gordura e nas exigências de energia e redução nas exigências de proteína para ganho de peso com elevação do PCV foram também verificadas por Fontes (1995), que constatou, em mestiços zebuíno $\mathrm{x}$ taurino, elevação nas exigências líquidas de energia para ganho de 3,32 a 4,03 Mcal/kg de ganho de PCV, considerando peso vivo de 300 e $450 \mathrm{~kg}$, respectivamente. Esses resultados são inferiores aos obtidos neste trabalho, no qual foram encontradas exigências energéticas para ganho de peso de 4,0 e 4,7 Mcal, respectivamente, para a mesma faixa de peso. Entretanto, para bovinos da raça Nelore, o valor de exigência líquida para ganho de peso neste estudo foi 5,5\% inferior ao estimado por Fontes
(1995), o que pode ser explicado, em parte, pelo menor teor de gordura corporal nos bovinos Nelore utilizados por Fontes (1995) em relação aos avaliados nesta pesquisa.

As exigências líquidas de proteína estimadas neste estudo foram inferiores às descritas por Fontes (1995), que, para a faixa de peso (300 a $450 \mathrm{~kg}$ ), obteve valores médios, para bovinos das raças Nelore e mestiços, estimados em 171 e $160 \mathrm{~g} / \mathrm{kg}$ de ganho de PCV, respectivamente.

Considerando um bovino com $450 \mathrm{~kg}$, as exigências líquidas de proteína estimadas neste trabalho $(143,5 \mathrm{~g})$ foram $4 \%$ inferiores e $28 \%$ às encontradas por Fontes (1995), para animais mestiços inteiros e castrados, respectivamente. Maior exigência de proteína para bovinos inteiros pode ser atribuída à sua maior síntese protéica em comparação aos animais castrados (NRC, 1996).

Comparativamente ao NRC (1996), verificou-se menor elevação nas exigências líquidas de energia para ganho (17,5 vs 35,6\%) e nas exigências líquidas de proteína para ganho (5,92 vs $31,1 \%)$ para peso de 300 a $450 \mathrm{~kg}$. Para um bovino de $450 \mathrm{~kg}$, as exigências líquidas de energia e proteína estimadas neste estudo foram aproximadamente $7 \%$ inferiores e $18 \%$ superiores às estimadas pelo NRC (1996), provavelmente em decorrência da condição sexual dos animais utilizados em ambos os estudos.

McDonald et al. (1995) constataram grande influência do peso sobre as exigências para ganho de peso. Considerando os pesos inicial e final de 50 e $500 \mathrm{~kg}$, os autores registraram decréscimo de 22,65\% (181 para $140 \mathrm{~g} / \mathrm{kg}$ ganho) nas exigências de proteína e aumento de $213 \%$ (1,84 para $5,76 \mathrm{Mcal} / \mathrm{kg}$ ganho) nas exigências líquidas de energia para ganho de peso. As exigências de proteína para ganho de peso, considerando peso vivo de $500 \mathrm{~kg}$, são bastante próximas às obtidas neste estudo (141,1 $\mathrm{g} / \mathrm{kg} \mathrm{GPCV})$. Entretanto, para exigências de energia, observou-se que os valores deste trabalho foram aproximadamente $15 \%$ inferiores ao verificado por esses autores.

De Campeneere et al. (2001), trabalhando com tourinhos inteiros de musculatura dupla (Belgian Blue), verificaram comportamento inverso ao observado neste estudo, ou seja, maiores exigências de proteína para ganho de peso com o aumento do peso vivo do animal, o que, segundo os autores, pode ser explicado pelo fato de os animais utilizados na pesquisa se encontrarem na fase ascendente da curva de crescimento, que se caracteriza por maiores acréscimos de tecido muscular em detrimento ao tecido adiposo.

Analisando dados referentes a 14 trabalhos da literatura nacional - Lana et al. (1992), Fontes (1995), Estrada et al. (1997), Ferreira et al. (1998), Paulino et al. (1999), Freitas et al. (2000), Véras et al. (2000), Véras et al. (2001), Silva et al. 
(2002), Veloso et al. (2002), Backes et al. (2002), Backes et al. (2002a), Almeida et al. (2001) e Berndt. et al (2002), entre outros - observaram-se, para um bovino de $450 \mathrm{~kg}$ de PV, exigências líquidas de energia e proteína para ganho de peso de 4,2 \pm 0,7 Mcal/kg GPCV e $154 \pm 27 \mathrm{~g} / \mathrm{kg} \mathrm{GPCV}$, respectivamente. Os valores de exigência líquida de energia e proteína para ganho de peso obtidos neste estudo encontram-se no intervalo estipulado para bovinos em condições brasileiras. Quando comparadas as exigências obtidas neste estudo com as estabelecidas pelo NRC (1996), verifica-se maior discrepância, principalmente quanto às exigências de proteína (aproximadamente $20 \%$ superiores).

\section{Conclusões}

O maior conteúdo de gordura no ganho de peso, em comparação à proteína, está associado ao aumento das exigências líquidas de energia e à diminuição das exigências líquidas de proteína com a elevação do peso corporal dos animais estudados.

Considerando-se que não houve diferenças significativas para exigências de energia e proteína para ganho de peso, é possível formular uma única ração para os animais Nelore puros e cruzados em condições semelhantes às deste trabalho.

\section{Literatura Citada}

AGRICULTURAL RESEARCH COUNCIL - ARC. The nutrient requirements of farm livestock. England: Commonwealth Agricultural Bureaux, 1980. 350p.

ALMEIDA, M.I.V.; FONTES, C.A.A.; ALMEIDA, F.Q. et al. Conteúdo corporal e exigências Líquidas de Energia e Proteína de Novilhos Mestiços Holandês-Gor em Ganho Compensatório. Revista Brasileira de Zootecnia, v.30, n.1, p.205-214, 2001.

BACKES, A.A.; PAULINO, M.F.; ALVES, D.D. et al. Requisitos líquidos de energia para ganho de novilhos de três grupos raciais, confinados em sistema de engorda. In: REUNIÃO ANUAL DA SOCIEDADE BRASILEIRA DE ZOOTECNIA, 39., 2002, Recife. Anais... Recife: Sociedade Brasileira de Zootecnia, 2002. CD-ROM, 2002.

BACKES, A.A.; PAULINO, M.F.; ALVES, D.D. et al. Composição corporal e requisitos líquidos de proteína para ganho de peso de novilhos de três grupos raciais, confinados em sistema de engorda. In: REUNIÃO ANUAL DA SOCIEDADE BRASILEIRA DE ZOOTECNIA, 39., 2002, Recife.Anais... Recife: Gmosis, 2002. CD-ROM. Nutrição de ruminantes. 6, NR-319.

BACKES, A.A.; SANCHEZ, L.M.B.; GONÇALVES, M.B.F. et al. Composição corporal e exigências líquidas de energia e proteína para ganho de peso de novilhos Santa Gertudis. Revista Brasileira de Zootecnia, v.31, n.6, p.2307-2313, 2002.

BERNDT, A.; HENRIQUE, W.; LEME, P.R. et al. Exigências líquidas de proteína e energia para crescimento de tourinhos Santa Gertrudis em dietas de alto teor de concentrado. Revista Brasileira de Zootecnia, v.31, n.5, p.2098-2104, 2002.

De CAMPENEERE, S.; FIEMS, L.O.; BOUCQUÉ, V.Ch. Energy and protein requirements of Belgian Blue double-muscle bulls.
Animal Feed Science and Technology, v.90, n.1, p.153167,2001

ESTRADA, L.H.C.; FONTES, C.A.A.; JORGE, A.M. et al Exigências nutricionais de bovinos não castrados em confinamento. 1. Conteúdo corporal e exigências líquidas de proteína e energia para ganho de peso. Revista Brasileira de Zootecnia, v.26, n.3, p.575-584, 1997 .

FERREIRA, M.A.; VALADARES FILHO, S.C.; COELHO DA SILVA, J.F. et al. Eficiência de utilização da energia metabolizável para ganho de peso e exigências de energia metabolizável e nutrientes digestíveis totais de bovinos F1 Simental x Nelore. Revista Brasileira de Zootecnia, v. 28 , n.2, p.368-387, 1999.

FERRELL, C.L.; JENKINS, T.G. Body composition and energy utilization by steers of diverse genotypes fed a high concentrate diet during the finishing period: II. Angus, Boran, Brahman, Hereford and Tuli sires. Journal of Animal Science, v.76, n.2 p.647-657, 1998.

FONTES, C.A.A. Composição corporal, exigências líquidas de nutrientes para ganho de peso e desempenho produtivo de animais zebuínos e mestiços europeu-zebu. Resultados experimentais. In: SIMPÓSIO INTERNACIONAL SOBRE EXIGÊNCIAS NUTRICIONAIS DE RUMINANTES, 1995 , Viçosa, MG. Anais... Viçosa, MG: Universidade Federal de Viçosa, 1995. p.419-455.

FREITAS, J.A.; FONTES, C.A.A.; SOARES, J.E. et al. Composição corporal e exigências de energia para mantença de bovinos (zebuínos e mestiços) e bubalinos não castrados, em confinamento. Arquivos de Ciências Veterinárias e Zoologia, v.3, n.1, p-19-29, 2000 .

GEAY, Y. Energy and protein in growing cattle. Journal of Animal Science, v.58, n.3, p.766-778, 1984.

HANKINS, O.G.; HOWE, P.E. Estimation of the composition of beef carcasses and cuts. Washington: USDA, 1946 (Technical bulletin, 926).

KOCK, S.W; PRESTON, R.L. Estimation of bovine carcass composition by the urea dilution technique. Journal of Animal Science, v.48 n.2, p.319-327, 1979.

LANA, R.P.; FONTES. C.A.A.; PERON, A.J. et al. Composição corporal e do ganho de peso exigências de energia, proteína e macroelementos minerais $(\mathrm{Ca}, \mathrm{P}, \mathrm{Mg}, \mathrm{Na}$ e $\mathrm{K}$ ) de novilhos de cinco grupos raciais. I Conteúdo corporal e do ganho de peso em gordura, proteína e energia. Revista Brasileira de Zootecnia, v.21, n.3, p.518-527,1992.

LOFGREEN, G.P. e GARRETT, W.N. A system for expressing net energy requeriments and feed values for growing and finishing beef cattle. Journal of Animal Science, v.27, n.3, p.793$806,1968$.

McDONALD, P.; EDWARDS, R.A.; GREENHALGH, J.F.D. et al Animal nutrition. 5.ed. Singapore: Longman, 1995. 607p.

NATIONAL RESEARCH COUNCIL - NRC. Nutrient requirements of beff cattle. 7.ed. Washington, D.C.: 1996. 242p.

OWENS, F.N.; DUBESKI, P.; HANSON, C.F. Factors that alter growth and development of ruminants. Journal of Animal Science, v.71, p.3138, 1993

PAULINO, M.F., FONTES, C.A.A. JORGE, A.M. et al. Exigências de energia para mantença de bovinos zebuínos não castrados em confinamento. Revista Brasileira de Zoootecnia, v.28, n.3, p.621-627,1999

PIRES, C,C.; FONTES, C.A.A.; GALVÃO, J.G. et al. Exigências nutricionais de bovinos em acabamento. I. Composição corporal e exigências de proteína e energia para ganho de peso. Revista Brasileira de Zootecnia, v.22, n.1, p.110-120, 1993.

REGAZZI, J.A. Teste para verificar a identidade de modelos de parâmetros e a identidade de modelos de regressão não linear. Revista Ceres, v.50, n.287, p.9-26, 2003

REID, J.T.; WHITE, D.; ANRIQUE, R.et al. Nutritional energetics of livestock: Some present boundaries of knowledge and future research needs. Journal of Animal Science, v.51, n.6, p.1393-1413, 1980. 
STATISTICAL ANALYSES SYSTEM - SAS. SAS/STAT. User's guide. 11.ed. Cary: 1995.

SILVA, D.J.; QUEIROZ, A.C. Análise de alimentos (métodos químicos e biológicos). 3.ed. Viçosa, MG: Universidade Federal de Viçosa, 2002. 235p

SILVA, F.F.; VALADARES FILHO, S.C.; ÍTAVO, L.C.V. et al. Composição corporal e requisitos energéticos e protéicos de Nelore, não castrados, alimentados com rações contendo diferentes níveis de concentrado e proteína. Revista Brasileira de Zootecnia, v.31, n.1, p.503-513, 2002 (supl. 1).

SNIFFEN, C.J.; O'CONNOR, J.D.; Van SOEST, P.J. et al. A net carbohydrate and protein system for evaluation cattle diets.: II Carbohydrate and protein availability. Journal of Animal Science, v.70, n.11, p.3562-3577, 1992.

TOELLE, V.D.; TESS, M.W.; JOHNSON, T. et al. Lean and fat patterns of serially slaughtered beef bulls fed different energy levels. Journal of Animal Science, v.63, n.8, p.1347-1360, 1986.

Van SOEST, P.J. Nutritional ecology of the ruminant. 2.ed. Ithaca: Cornell University, 1994. 476p.

VELOSO, C.M.; VALADARES FILHO, S.C.; GESUALDI Jr. et al. Eficiência de utilização da energia metabolizável para mantença e ganho de peso e exigências de energia metabolizável e de nutrientes digestíveis totais de bovinos $\mathrm{F} 1$ Limousin $\mathrm{x}$ Nelore não castrados. Revista Brasileira de Zootecnia, v.31, n.3, p.1286-1293, 2002 .

VÉRAS, A.S.C.; VALADARES FILHO, S.C.; COELHO DA SILVA, J.F. et al. Composição corporal e requisitos energéticos e protéicos de Nelore, não castrados, alimentados com rações contendo diferentes níveis de concentrado. Revista Brasileira de Zootecnia, v.29, n.6, sup1.2, p.2379-2389, 2000.

VÉRAS, A.S.C.; VALADARES FILHO, S.C.; COELHO DA SILVA, J.F.et al. Predição da composição corporal e dos requisitos de energia e proteína para ganho de peso de bovinos, não castrados alimentados com rações contendo diferentes níveis de concentrado. Revista Brasileira de Zootecnia, v.30, n.3, supl.1, p.1127-1134, 2001. 